\title{
Radiotherapy after prostatectomy in high-risk prostate cancer
}

\author{
G. Roviello ${ }^{1}$ (D. Dillari ${ }^{2} \cdot$ G. Nesi ${ }^{3} \cdot$ B. Detti ${ }^{4}$
}

Received: 2 March 2020 / Accepted: 16 March 2020

(c) Federación de Sociedades Españolas de Oncología (FESEO) 2020

\section{Dear Editor,}

We congratulate Casas et al. [1] for their work on the role of postoperative adjuvant and early salvage radiotherapy after prostatectomy in high-risk prostate cancer. In this paper, the authors compared radical prostatectomy plus adjuvant radiotherapy and early salvage radiotherapy versus salvage radiotherapy. Postoperative PSA values guided the decision for radiotherapy. A total of 204 patients with prostate cancer were evaluated. The authors concluded that adjuvant radiotherapy and early salvage radiotherapy (specifically considering increases from 0.00 to $<0.3$ ) can benefit disease-free, cause-specific, metastasis-free, and overall survival in patients with prostate cancer and several high-risk pathological factors after radical prostatectomy. In line with these data, we previously showed that adjuvant radiotherapy could be the best choice for those patients with adverse prognostic factors; in particular, we found that positive surgical margins and detectable postoperative PSA are the most important risk factors concerning recurrence after radical prostatectomy [2].

More recently it has been reported that salvage radiotherapy and adjuvant radiotherapy offer similar outcomes for event-free survival, although the use of salvage radiotherapy is preferred since side-effects are lower compared with adjuvant radiotherapy [3,4]. Although we confirm the need to

This comment refers to the article available online at https://doi. org/10.1007/s12094-018-1931-3.

G. Roviello

giandomenicoroviello@hotmail.it

1 Department of Health Sciences, University of Florence, viale Pieraccini, 6, 50139 Florence, Italy

2 Department of Urology, University of Florence, Careggi Hospital, Florence, Italy

3 Division of Pathological Anatomy, Department of Health Sciences, University of Florence, 50139 Florence, Italy

4 Radiotherapy Unit, Department of Oncology, AOU Careggi, Florence, Italy redefine the role of adjuvant radiotherapy after radical prostatectomy, we believe that adjuvant radiotherapy should be the first choice in men with prostate cancer and high-risk pathological factors after radical prostatectomy.

In addition, growing evidence suggests that the cumulative length of the positive surgical margin together with the tumor grade at margins of resection are independent predictors of biochemical recurrence [5]. Detailed histopathologic assessment of surgical margins may therefore support clinical decision-making with regard to postoperative radiotherapy recurrence [6].

Funding No funding.

\section{Compliance with ethical standards}

Conflict of interest The other authors declare that there are no conflicts of interest in this work.

Research involving human participants and/or animals This article does not contain any studies with human participants or animals performed by any of the authors.

Informed consent For this type of study, no informed consent is required.

\section{References}

1. Casas F, Valduvieco I, Oses G, Izquierdo L, Archila I, Costa M, Cortes KS, Barreto T, Ferrer F. Postoperative adjuvant and very early salvage radiotherapy after prostatectomy in high-risk prostate cancer patients can improve specific and overall survival. Clin Transl Oncol. 2019;21(3):355-62.

2. Detti B, Scoccianti S, Cassani S, Cipressi S, Villari D, Lapini A, Saieva C, Cai T, Pertici M, Giacomelli I, Livi L, Ceroti M, Nicita G, Carini M, Biti G. Adjuvant and salvage radiotherapy after prostatectomy: outcome analysis of 307 patients with prostate cancer. J Cancer Res Clin Oncol. 2013;139(1):147-57.

3. Parker C, Clarke NW, Cook A, et al. Timing of radiotherapy (RT) after radical prostatectomy (RP): first results from the 
RADICALS RT randomised controlled trial (RCT). Ann Oncol. 2019;30(5):v851-v934.

4. Vale CL, Brihoum M, Chabaud S, et al. Adjuvant or salvage radiotherapy for the treatment of localised prostate cancer? A prospectively planned aggregate data meta-analysis. Ann Oncol. 2019;30(5):v851-v934.

5. Brimo F, Partin AW, Epstein JI. Tumor grade at margins of resection in radical prostatectomy specimens is an independent predictor of prognosis. Urology. 2010;76(5):1206-9.

6. Hollemans E, Verhoef EI, Bangma CH, et al. Prostate carcinoma grade and length but not cribriform architecture at positive surgical margins are predictive for biochemical recurrence after radical prostatectomy. Am J Surg Pathol. 2020;44(2):191-7.

Publisher's Note Springer Nature remains neutral with regard to jurisdictional claims in published maps and institutional affiliations. 